\title{
INFLUENCE OF TEMPERATURE AND RELATIVE HUMIDITY ON GRAIN STERILITY IN RICE
}

\author{
D. SUMITH DE Z. ABEYSIRIWARDENA*, K. OHBA and A. MARUYAMA \\ Rice Research \& Development Institute, Batalagoda, Ibbagamuwa. \\ National Agricultural Experiment Station, Nishigoshi, Kumamoto, 861-11, Japan
}

(Received: 29 January 2002 ; accepted: 01 July 2002)

\begin{abstract}
Almost complete and uniform grain sterility in rice over large areas has become a serious problem in the warm and humid lowland region in Sri Lanka. In view of this, the influence of high temperature at low and very high relative humidity (RH) levels and normal temperature at very low and normal $\mathrm{RH}$ levels on the spikelet surface temperature and grain sterility in rice at heading were studied under controlled environments. Almost complete grain sterility in rice was induced by high temperature $\left(35^{\circ} \mathrm{C}\right.$ day $/ 30^{\circ} \mathrm{C}$ night) when coupled with high $\mathrm{RH}(85-90 \%)$ at heading. Reduction in $\mathrm{RH}$ by $30 \%$ at high temperature resulted in decrease in grain sterility but made no significant increase in the completely filled grain percentage which was negligibly low at both very high and low $\mathrm{RH}$ levels. Under the normal temperature of $30^{\circ} \mathrm{C}$ day $/ 25^{\circ} \mathrm{C}$ night, about two-fold increase in grain sterility at very low $\mathrm{RH}$ ( 35 - 40\%) over the lowest recorded $13.8 \%$ grain sterility at normal $\mathrm{RH}$ (65-70\%) was observed. Percent partially filled grains were not found to be influenced by both temperature and $\mathrm{RH}$ of the surrounding atmosphere. The spikelet surface temperature in rice was always several degrees less than the atmospheric temperature and increase in atmospheric temperature at heading resulted in increase in spikelet surface temperature. At a given atmospheric temperature, higher the RH, higher the spikelet surface temperature at heading. Spikelet surface optimum and critical high temperatures for grain sterility appeared to be around $26^{\circ} \mathrm{C}$ and between $26^{\circ} \mathrm{C}$ and $31^{\circ} \mathrm{C}$ but close to $31^{\circ} \mathrm{C}$, respectively.
\end{abstract}

Key words: Grain sterility, heading, relative humidity, rice, spikelet, temperature.

\section{INTRODUCTION}

The problem of grain sterility in rice (Oryza sativa L.) has been reported in most of the agro-climatic zones in both Dry (Yala - from mid March to August) and Wet (Maha - from mid September to February in the following year) seasons in Sri Lanka. ${ }^{2}$ Grain sterility in rice which has often been reported in the Midland and Highland regions of Sri Lanka, has been mainly attributed to low temperature injury. ${ }^{6}$ The low temperature recorded in these regions during reproductive and maturity phases of the rice crop varies between 14.5 and $19.5^{\circ} \mathrm{C} .{ }^{1}$ This so-called sterility in rice in Sri Lanka has become a serious field problem making entire rice tracts amounting to several hectares almost completely sterile not only in the Midland and Upland regions but also in the Lowland region in recent years. Sterility in rice during the Maha season in the Low Country region may be attributed to low

* Corresponding Author 
temperature $\left(19-17^{\circ} \mathrm{C}\right)$ condition during the reproductive phase in rice. ${ }^{3}$ Night temperatures of less than $19^{\circ} \mathrm{C}$ which is the critical low temperature for inducing grain sterility in rice ${ }^{5}$ have been recorded during the Maha season in the Lowland region during the young microspore stage of the rice crop. However, factors affecting almost complete and uniform grain sterility in rice over large areas in the Yala season have not been studied-adequately. Grain sterility in rice in the Yala season has been termed 'Ehala Pussa' in Sinhala by farmers to mean 'empty grain in the Yala season'. The term 'sterility' is often used loosely without correct distinction between unfertilized and partially filled grains. ${ }^{12}$ However, Morita and Dhanapala ${ }^{4}$ studied the factors affecting sterility in rice in both the Yala and Maha seasons in Sri Lanka making a clear distinction between unfertilized and partially filled grains. They reported that although the main problem they observed in the samples they examined was partially filled grains due to the damage of pests and diseases, some samples showed a very low percentage of fertility.

Almost complete and uniform sterility in rice over large areas may not be attributed to damage due to pests, diseases or soil problems since damages due to such factors are commonly patchy. In most parts of the Lowland region in the Yala season in Sri Lanka, temperature during anthesis of the rice crop is higher than $30^{\circ} \mathrm{C}^{1}$ and sometimes reaches even up to $35^{\circ} \mathrm{C}$. During this period wind velocity is also high thus making the conditions very favorable for pollen desiccation. Satake and Yoshida ${ }^{9}$ reported that high temperature induced sterility in rice in areas where the rice growing season had been shifted due to the introduction of modern cultivars. Sato et al. ${ }^{10}$ reported that at $35^{\circ} \mathrm{C}$ day $/ 30^{\circ} \mathrm{C}$ night temperatures, grain sterility increases as a result of comparatively smaller pollen and non-dehiscence of anthers. Abeysiriwardena ${ }^{1}$ emphasized the importance of high temperature and relative humidity with respect to almost complete and uniform grain sterility in rice over large areas during the Yala season in Sri Lanka. Although the influence of high temperature on grain sterility in rice has been studied, ${ }^{7,9,10}$ literature on the combined effect of relative humidity and temperature which may be the most probable condition causing grain sterility of the Yala rice crop in Sri Lanka, is lacking. On the other hand, spikelet surface temperature which may be dependent on both the atmospheric temperature and $\mathrm{RH}$, may be more associated with grain sterility than just atmospheric temperature around the rice plant. However, literature on the influence of atmospheric temperature and $\mathrm{RH}$ on spikelet surface temperature is also lacking. Therefore, the objective of the present study was to investigate the influence of different levels of relative humidity at high and normal levels of temperature on spikelet surface temperature and grain sterility in rice under controlled environments.

\section{METHODS AND MATERIALS}

The experiment was conducted in 1999/2000 in growth chambers at the Kyushu National Agricultural Experiment Station, Kumamoto, Kyushu, Japan, where both 
the temperature and relative humidity were controlled. The popular Japanese rice cultivar 'Hinohikari' was used in the experiment with four treatment combinations; normal temperature $30^{\circ} \mathrm{C}$ day $(12 \mathrm{~h}) / 25^{\circ} \mathrm{C}$ night $(12 \mathrm{~h})$ and normal relative humidity (RH) $65-70 \%$ (control), normal temperature $30^{\circ} \mathrm{C}$ day $(12 \mathrm{~h}) / 25^{\circ} \mathrm{C}$ night $(12 \mathrm{~h})$ and very low $\mathrm{RH} 35-40 \%$, high temperature $35^{\circ} \mathrm{C}$ day $(12 \mathrm{~h}) / 30^{\circ} \mathrm{C}$ night $(12 \mathrm{~h})$ and high $\mathrm{RH} 85-90 \%$, high temperature $35^{\circ} \mathrm{C}$ day $(12 \mathrm{~h}) / 30^{\circ} \mathrm{C}$ night $(12 \mathrm{~h})$ and low $\mathrm{RH} 55$ $60 \%$. Temperature and humidity levels in the treatment combinations were selected in order to represent the varying temperature and humidity conditions found in the field during the anthesis of the rice crop in the Yala season in Sri Lanka. Yoshida ${ }^{11}$ reported that critical high and optimum atmospheric temperatures with respect to grain sterility in rice were $35-36^{\circ} \mathrm{C}$ and $30-33^{\circ} \mathrm{C}$, respectively. Although a factorial experiment would have been the ideal, the number of treatment combinations had to be limited to four depending on the availability of growth chambers within the study period.

A separate growth chamber was used for each treatment combination enclosing all three replicates and all the other conditions were maintained the same among all four growth chambers. Thus, the experiment was considered to be laid out in a fully randomized design with three replications assuming no confounding effects between treatments and growth chamber conditions with respect to grain sterility and spikelet surface temperature. Each replicate of each treatment was represented by a single pot with $3-4$ rice plants having $8-10$ panicles.

Rice plants of all four treatments were raised in pots and grown under $28^{\circ} \mathrm{C}$ and $70 \% \mathrm{RH}$ with adequate nutrients in one growth chamber until heading at which stage the plants were exposed to different treatments. Heading is the most sensitive stage to high temperature in rice., ${ }^{7,89}$ Thereafter; plants were kept under the respective treatment combinations until maturity.

The surface temperature of the spikelets was measured at anthesis on six panicles from each replicate in each treatment using an electronic infrared thermometer (model CT - 30). The emissivity on the spikelet surface was assumed to be 1.0. Care was taken to measure temperature only on the surface of the spikelets but not the temperature in the surrounding micro environment of spikelets. At maturity, panicles in each replicate in each treatment combination were harvested separately. The number of completely filled, partially filled and empty grains (sterile spikelets) were counted and their percentages were computed. Percentage data were transformed using arc sign transformation as percentages outside the range of $30-70 \%$ were observed, before subjecting for analysis of variance.

\section{RESULTS}

In the present study, a clear distinction was made between partially filled and unfertilized empty grains. Fertility of spikelets was identified by pressing them 
with fingers ${ }^{9}$ followed by opening the spikelets with care and observing the ovary. Spikelets with undeveloped ovaries which are normally less than $1.5 \mathrm{~mm}$ in length were classified as unfertilized ${ }^{4}$ and the rest as fertilized. Since no damage due to pests and diseases was observed in any of the samples as the plants were grown in growth chambers, all the empty grains were classified as unfertilized or sterile. The number of seeds counted to estimate necessary parameters per pot varied from 1548 to 2110 confirming that an adequate seed sample size was used per replicate per treatment. Since plants were supplied with adequate nutrients, no plant showed any nutrient deficiency so that any unpredictable variability due to nutrient deficiencies on grain sterility has been avoided.

Table 1: Different grain categories as percentage, sterile, partially filled and completely filled grains in rice cultivar 'Hinohikari' when exposed to different combinations of temperature and relative humidity $(\mathrm{RH})$ levels at heading.

\begin{tabular}{lcccc}
\hline $\begin{array}{c}\text { Combination of temperature and } \\
\text { RH levels }\end{array}$ & \multicolumn{3}{c}{ Grain category } \\
Temperature & $\begin{array}{c}\text { RH } \\
(\%)\end{array}$ & $\begin{array}{c}\text { Sterile } \\
(\%)\end{array}$ & $\begin{array}{c}\text { Partally filled } \\
(\%)\end{array}$ & $\begin{array}{c}\text { Completely filled } \\
(\%)\end{array}$ \\
\hline $30^{\circ} \mathrm{C}$ day $/ 25^{\circ} \mathrm{C}$ night & $35-40$ & 26.5 & 11.2 & 62.3 \\
& $65-70$ & 13.8 & 6.2 & 80.0 \\
$35^{\circ} \mathrm{C}$ day $/ 30^{\circ} \mathrm{C}$ night & $55-60$ & 78.4 & 14.5 & 7.1 \\
& $85-90$ & 87.7 & 7.9 & 4.4 \\
LSD (0.05) for transformed data & 6.4 & $\mathrm{NS}^{\mathrm{a}}$ & 4.9 \\
$\mathrm{CV} \%$ & & 8.3 & 25.0 & 8.3 \\
\hline
\end{tabular}

${ }^{a}$ NS- Indicates not significant at 5\% probability level.

Percent sterile, partially filled and completely filled grains of rice cultivar 'Hinohikari' when exposed to different combinations of temperature and RH levels at heading are presented in Table 1 . Validity of the results presented in Table 1 is confirmed by comparatively low CVs for percent sterile and completely filled grains that varied significantly between treatments. However, percent partially filled grains for which the $\mathrm{CV}$ appeared to be too high, did not vary significantly between treatments. The reason for high CV for percent partially filled grains is the low overall average but not the elevated error term. Although the original percentage data are presented, all the comparisons are made on transformed data. 
Table 2: Surface temperature of the spikelets in rice cultivar 'Hinohikari' when exposed to different combinations of atmospheric temperature and relative humidity (RH) levels at heading.

\begin{tabular}{|c|c|c|}
\hline \multicolumn{2}{|c|}{ Combinations of temperature and $\mathrm{RH}$ levels } & \multirow{2}{*}{$\begin{array}{c}\text { Spikelet surface temperature } \\
\left({ }^{\circ} \mathrm{C}\right)\end{array}$} \\
\hline Temperature & $\mathrm{RH}(\%)$ & \\
\hline \multirow[t]{2}{*}{$30^{\circ} \mathrm{C}$ day $/ 25^{\circ} \mathrm{C}$ night } & $35-40$ & 23.6 \\
\hline & $65-70$ & 26.0 \\
\hline \multirow[t]{2}{*}{$35^{\circ} \mathrm{C}$ day $/ 30^{\circ} \mathrm{C}$ night } & $55-60$ & 31.4 \\
\hline & $85-90$ & 32.9 \\
\hline LSD (0.05) & & 0.9 \\
\hline CV\% & & 2.5 \\
\hline
\end{tabular}

We measured the temperature on the surface of the spikelets at heading in our experiment to see how it bridges the atmospheric temperature and grain sterility in rice. Surface temperature of the spikelets at heading under different combinations of temperature and $\mathrm{RH}$ levels are presented in Table 2 . Validity of the results presented in Table 2 is confirmed by comparatively low CV for spikelet surface temperature that varied significantly between treatments.

\section{DISCUSSION}

The treatment with $30^{\circ} \mathrm{C}$ day $/ 25^{\circ} \mathrm{C}$ night and $65-70 \%$ RH (normal temperature and $\mathrm{RH}$ found in the field) was considered as the control of which the lowest and the normal level of $13.8 \%$ grain sterility was observed. Even under the normal temperature of $30^{\circ} \mathrm{C}$ day $/ 25^{\circ} \mathrm{C}$ night, very low $\mathrm{RH}(35-40 \%)$ has significantly increased the grain sterility up to $26.5 \%$ (Table 1 ). Loss of pollen viability or reduction of pollen germination on stigma surface due to desiccation may be the reason for increased grain sterility under very low $\mathrm{RH}$. Thus, increased grain sterility in rice observed sometimes under the normal day temperature of $30^{\circ} \mathrm{C}$ in the field may be attributed to very low $\mathrm{RH}$ and such a low $\mathrm{RH}$ can be observed in paddy fields on days with dry winds. Meteorological data available in the Department of Agriculture show that $\mathrm{RH}$ values as low as $35-40 \%$ have been observed occasionally on sunny days with dry winds called 'Kachchan' during the months when the rice crops are heading in the Dry Zone (Personal communication with Dr. B.V.R. Punyawardena, Meteorological Unit, Natural Resource Management Center, Department of Agriculture, Peradeniya, Sri Lanka). During the high temperature of $35^{\circ} \mathrm{C}$ day $/ 30^{\circ} \mathrm{C}$ night, at both low (55-60\%) and high $(85-90 \%) \mathrm{RH}$ levels at heading, the grain sterility has been increased (Table 1). This is in agreement with the results of Sato et al. $^{10}$ and Satake and Yoshida ${ }^{9}$ who reported 
high temperature induced grain sterility at heading in rice. Temperature appeared to be the main factor causing grain sterility in rice followed by $\mathrm{RH}$. However, high temperature coupled with high $\mathrm{RH}$ caused the highest damage in rice, inducing almost complete grain sterility $(87.7 \%$ ) while high temperature coupled with low $\mathrm{RH}$ induced grain sterility was $78.4 \%$. Thus, high temperature coupled with high $\mathrm{RH}$ appeared to be the most effective condition to induce grain sterility in rice and that may be the condition associated with almost complete and uniform socalled grain sterility in rice over large areas in the Yala season in Sri Lanka. Under such conditions moderate winds to reduce spikelet surface temperature at heading may be beneficial for the rice crop.

Percent completely filled grains also varied significantly between treatments. Percent completely filled grains at high temperature were lower than those at normal temperature. No significant difference in percent completely filled grains was observed between low $(55-60 \%)$ and high $(85-90 \%)$ RH levels at high temperature suggesting that even a $30 \%$ reduction in $\mathrm{RH}$ could not improve completely filled grain percentage at high temperature. The reason may be that the difference in $\mathrm{RH}$ will not influence grain filling as it is a 'source - sink' relationship influenced by photosynthesis and respiration. One could suspect that low $\mathrm{RH}$ could have an indirect influence on grain filling perhaps due to lesser stomatal opening when compared to higher RH. Testing for this by determining the degree of stomatal opening is beyond the present study. However, $30 \%$ reduction in $\mathrm{RH}$ at high temperature significantly reduced the percent grain sterility. Therefore, at high temperatures, reduction in $\mathrm{RH}$ though it decreased grain sterility, may not be a solution for increase in completely filled grains. In contrast, percent completely filled grains under normal $\mathrm{RH}(65-70 \%)$ was significantly higher than those at very low $\mathrm{RH}(35-40 \%)$ at the normal temperature $\left(30^{\circ} \mathrm{C}\right.$ day $/ 25^{\circ} \mathrm{C}$ night $)$. This is because at normal temperature, very low $\mathrm{RH}$ has increased the percent sterility over that at normal $\mathrm{RH}$. Temperature and $\mathrm{RH}$ had no influence on percent partially filled grains. This indicates that once fertilization has taken place, grain development is independent of both temperature and $\mathrm{RH}$ ranges used in the surrounding atmosphere of the rice plant in the present study. However, high variability in comparison to the overall average indicated by a high CV (25\%) associated with percent partially filled grains suggests that the percent partially filled grains are mainly influenced by some factor (other than temperature and $\mathrm{RH})$. This, perhaps, may be the 'source - sink' relationship.

When the $\mathrm{RH}$ levels were compared within each of the atmospheric temperature levels, spikelet temperature was lower at low $\mathrm{RH}$ than at high $\mathrm{RH}$ (Table 2). The reason may be that the lower the $\mathrm{RH}$, the higher the transpiration, thus increasing the heat of vapourisation and decreasing the temperature on the surface of spikelets. At $35^{\circ} \mathrm{C}$ day $/ 30^{\circ} \mathrm{C}$ night temperature, the spikelet surface temperature under the $85-90 \% \mathrm{RH}$ was increased up to $32.9^{\circ} \mathrm{C}$ causing a higher damage (higher grain sterility) than that under $55-60 \% \mathrm{RH}$ where the spikelet 
surface temperature was $31.4^{\circ} \mathrm{C}$. This suggests that the higher the atmospheric $\mathrm{RH}$, the higher the surface temperature of spikelets resulting in higher grain sterility within the high temperature range at the heading stage used in the study. It is well known that low temperature plus wind contributes to the 'wind chill factor' which damages crops in temperate latitudes. In the present study, it is interesting to note that high temperature plus high humidity could contribute to a heat stress factor' in tropical crops. In this situation, the true cause of increased grain sterility at high RH is not known but one can suspect that it may be due to comparatively smaller pollens and non-dehiscence of anthers caused by high temperature as reported by Sato et al. ${ }^{10}$ However, the situation appeared different at low temperature $\left(30^{\circ} \mathrm{C}\right.$ day $/ 25^{\circ} \mathrm{C}$ night) where very low humidity $(35-40 \%)$ causing comparatively lower spikelet surface temperature $\left(23.6^{\circ} \mathrm{C}\right)$ increased grain sterility in rice. In this situation, any effect of high temperature on grain sterility is remote because grain sterility at normal $\mathrm{RH}$ where the spikelet surface temperature was $26^{\circ} \mathrm{C}$, was the lowest (13.8). Thus, increased grain sterility may be due to pollen desiccation caused by low $\mathrm{RH}$.

Higher the atmospheric temperature, higher the spikelet surface temperature at heading in rice. In general, spikelet surface temperature was always several degrees less than the atmospheric temperature used in the study. Reduction in atmospheric $\mathrm{RH}$ by about $30 \%$ resulted in decrease in temperature on the surface of the rice spikelets by about 1.5 and $2.5^{\circ} \mathrm{C}$ at the atmospheric temperatures of $35^{\circ} \mathrm{C}$ day $/ 30^{\circ} \mathrm{C}$ night and $30^{\circ} \mathrm{C}$ day $/ 25^{\circ} \mathrm{C}$ night, respectively. Thus, the surface temperature of the rice spikelets appeared to be dependent not only upon the atmospheric temperature but also upon the atmospheric $\mathrm{RH}$ level within the temperature range at heading used in the study. Yoshida ${ }^{11}$ reported critical high and optimum atmospheric temperatures for grain sterility in rice. However, spikelet surface optimum and critical high temperatures for grain sterility in rice have not been reported. Results of the present study suggest that the optimum spikelet surface temperature for grain sterility in rice should be around $26^{\circ} \mathrm{C}$ which is associated with grain sterility as low as $13.8 \%$. The critical high spikelet surface temperature for grain sterility in rice should be between $26^{\circ} \mathrm{C}$ and $31^{\circ} \mathrm{C}$ but closer to $31^{\circ} \mathrm{C}$ which is associated with grain sterility as high as $78.4 \%$.

A japonica rice has been used in the present study. Conducting a similar study using a set of different indica rice varieties would be interesting and results of such a study would be comparatively more applicable to Sri Lanka where only indica rice is grown. Furthermore, in Sri Lanka, high winds are frequent at the time of heading during the Yala season rice crop where incidence of so-called sterility is high. Thus, an investigation on the influence of different wind velocities under different temperatures at heading on grain sterility in rice would also be interesting. 


\section{Acknowledgement}

This study was conducted at the Kyushu National Agricultural Experiment Station, Japan, under the sponsorship of JISTEC, Japan. The authors wish to express their sincere thanks to JISTEC for providing funds and making necessary arrangements to conduct this study in Japan. The principal author also wishes to extend his sincere appreciation to Dr. S.D.G. Jayawardena, Director General, Department of Agriculture, Sri Lanka, for giving necessary approval to conduct this study in Japan.

\section{References}

1 Abeysiriwardena D.S. de Z. (1999). Influence of temperature on rice in Sri Lanka. Report of the Kyushu Chapter of the Society of Agricultural Meteorology of Japan. II (8): 77 - 90.

2 Gunawardena S.D.I.E. (1980). Rice research and IRTP involvement in Sri Lanka. Rice Improvement in China and Asian countries. pp. 261 - 279. IRRI, Philippines.

3 Jayawardena S.D.G. \& P.E. Peiris. (1980). Problems and potentials of rice cultivation in the Wet Zone. In Rice Symposium 80. Department of Agriculture, pp. 33 - 46. Sri Lanka.

4 Morita H. \& M.P. Dhanapala. (1990). So-called grain sterility of rice in Sri Lanka in 1985 Yala and 1985-86 Maha cropping seasons. Japan J. Trop. Agr. 34 (1): 20-26.

$5 \quad$ Nishiyama I.N., N. Nito H. Hayse \& T. Satake. (1969). Protecting effect of temperature and depth of irrigation water from sterility caused by cooling treatment at the meiotic stage of rice plants [in Japanese]. Proc. Crop Sci. Soc. Jpn. 38: 554 - 555 .

6 Ota. Y. \& N. Devasundarajah. (1966). Part-3 Effect of low temperature on growth and sterility in indica rice. Japan J. Trop. Agr. 9: 158 - 161.

7 Satake T. \& S. Yoshida. (1977 a). Mechanism of sterility caused by high temperature at flowering time in indica rices. JARQ 11: 127 - 128.

8 Satake T. \& S. Yoshida. (1977 b). Critical temperature and duration for high temperature induced sterility in indica rice. JARQ 11: 190 - 191.

9 Satake T. \& S. Yoshida. (1978). High temperature-induced sterility in indica rice at flowering. Jpn. J. Crop Sci. 47: 6 - 17. 
10 Sato K., K. Inaba \& M. Tozawa. (1973). High temperature injury of ripening in rice plant. 1. The effects of high temperature treatments at different stages of panicle development on the ripening. Proc. Crop Sci. Soc. Jpn. 42: 207 $-213$.

11 Yoshada S. (1978). Tropical climate and its influence on rice. IRRI Res. Pap. Ser. 20 - 25 pp.

12 Yoshida S. (1981). Physiological analysis of rice yield. In: Fundamentals of Rice Crop Science. (Ed. S, Yoshida) pp. 231 - 251. IRRI, Philippines. 